\section{JURNAL EKONOMI EFEKTIF}

ISSN : $2622-8882$, E-ISSN : 2622-9935

Jurnal Ekonomi Efektif, Vol. 4, No. 1, Oktober 2021 @Prodi Manajemen Fakultas Ekonomi Universitas Pamulang

\title{
PENGARUH STRATEGI PROMOSI TERHADAP KEPUTUSAN PEMBELIAN KONSUMEN PADA ALFAMART PONDOK PUCUNG KOTA TANGERANG SELATAN
}

\author{
Adi Prihanto ${ }^{1}$, Ali Huzaifi ${ }^{2}$, Idvan ${ }^{3}$, Yopi ${ }^{4}$, Udin Ahidin ${ }^{5 *}$ \\ Universitas Pamulang, Tangerang Selatan, Banten, Indonesia \\ adi.prihanto@bppt.go.id ${ }^{1}, \underline{\text { aly.who@gmail.com }}{ }^{2}$, idvan@ $@$ bpt.go.id $^{3}$, \\ yopiopink567@ gmail.com ${ }^{4}, \underline{\text { dosen00406@ unpam.ac.id }{ }^{5^{*}}}$
}

Manuskrip: September -2021; Ditinjau: September: -2021; Diterima: September-2021; Online: Oktober-2021; Diterbitkan: Oktober-2021

\begin{abstract}
ABSTRAK
Penelitian ini bertujuan untuk mengetahui pengaruh strategi promosi terhadap keputusan pembelian konsumen pada Alfamart Pondok Pucung-Kota Tangerang Selatan. Metode yang digunakan adalah explanatory research dengan sampel sebanyak 100 responden. Teknik analisis menggunakan analisis statistik dengan pengujian regresi, korelasi, determinasi dan uji hipotesis. Hasil penelitian ini variabel strategi promosi diperoleh nilai rata-rata skor sebesar 3,414 dengan kriteria baik. Variabel keputusan pembelian diperoleh nilai rata-rata skor sebesar 3,841 dengan kriteria baik. Strategi promosi berpengaruh positif dan signifikan terhadap keputusan pembelian dengan nilai persamaan regresi $\mathrm{Y}=9,323+0,852 \mathrm{X}$, dan nilai koefisien korelasi 0,777 atau memiliki tingkat hubungan yang kuat dengan nilai determinasi $60,3 \%$. Uji hipotesis diperoleh signifikansi $0,000<0,05$.
\end{abstract}

Kata Kunci: Strategi Promosi, Keputusan Pembelian

\begin{abstract}
This study aims to determine the effect of promotional strategies on consumer purchasing decisions at Alfamart Pondok Pucung-South Tangerang City. The method used is explanatory research with a sample of 100 respondents. The analysis technique uses statistical analysis with regression, correlation, determination and hypothesis testing. The results of this research variable promotion strategy obtained an average score of 3,414 with good criteria. The purchase decision variable obtained an average score of 3.841 with good criteria. The promotion strategy has a positive and significant effect on purchasing decisions with the value of the regression equation $Y=9.323+0.852 X$, and the correlation coefficient value of 0.777 or has a strong relationship with a determination value of 60.3\%. Hypothesis testing obtained a significance of $0.000<0.05$.
\end{abstract}

Keywords: Promotion Strategy, Purchase Decision 


\section{PENDAHULUAN}

\section{A. Latar Belakang Masalah}

Kondisi dunia bisnis saat ini telah berkembang menjadi semakin pesat, semakin kompleks, semakin kompetitif, bergerak dengan cepat serta semakin sulit untuk diprediksi. Konsumsi masyarakat terhadap kebutuhan barang dan jasa yang beragam dirasakan semakin berkembang. Hal tersebut terjadi seiring dengan pengaruh kemajuan industri dalam kegiatan perdagangan dan pemasaran internasional, yang juga dapat dirasakan di Indonesia. Semakin tinggi tingkat persaingan mengakibatkan setiap perusahaan saling bersaing dalam mempertahankan konsumen. Sehingga mengakibatkan persaingan antar perusahaan yang sejenis maupun perusahaan yang memproduksi barang-barang substitusi tidak dapat dihindari lagi.

Berbagai tantangan bisnis yang ada menuntut perusahaan untuk memiliki kemampuan respon yang cepat dan fleksibel terhadap setiap peluang, ancaman dari luar, tuntutan pelanggan, bahkan langkah-langkah kompetitor. Agar perusahaan unggul dalam persaingan, dibutuhkan perencanaan yang matang mengenai kegiatan pemasaran, seperti produk yang akan dipasarkan, harga yang menarik dan terjangkau oleh pelanggan, serta bagaimana perusahaan mempromosikan produknya dengan pelanggan ataupun dengan pihak-pihak lain yang berkepentingan.

Pemasaran adalah kegiatan manusia yang diarahkan untuk memenuhi kebutuhan dan keinginan melalui proses pertukaran. Strategi pemasaran yang sering dilakukan oleh perusahaan yaitu, dengan menggunakan unsur-unsur peralatan promosi atau yang lebih di kenal dengan bauran promosi. Bauran promosi terdiri dari periklanan, promosi penjualan, humas dan publisitas, pemasaran langsung, dan penjualan secara pribadi.

PT Alfamart cabang Pondok Pucung-Kota Tangerang Selatan merupakan salah satu usaha waralaba yang bergerak dalam bidang retail. Untuk dapat bersaing dengan kompetitor perusahaan sejenisnya seperti : Indomart, Superindo, Circle K, Seven Eleven dan perusahaan sejenis lainnya. PT Alfamart cabang Pondok Pucung-Kota Tangerang Selatan harus mampu mempertahankan pelanggan bahkan untuk menarik pelanggan baru.

Promosi penjualan pada dasarnya merupakan pemberian atau penggunaan insentifinsentif untuk mendorong penjualan produk yang ditawarkan oleh perusahaan baik itu berupa barang-barang ataupun jasa yang ditawarkan oleh calon pembeli atau konsumen dapat mengetahui keberadaan produk atau jasa dan tertarik untuk membelinya.

Promosi penjualan menurut Fandy Tjiptono $(2011 ; 229)$ adalah "bentuk persuasi langsung melalui penggunaan berbagai insentif yang dapat diukur untuk merangsang pembelian produk dengan segera dan meningkatkan jumlah barang yang dibeli pelanggan".

Perusahaan membutuhkan komunikasi dengan pelanggannya yaitu dengan cara melakukan promosi, semakin gencar peusahaan melakukan promosi maka akan semakin dekat di benak pelanggannya. Oleh karena itu banyak perusahaan yang berani mengeluarkan anggaran yang cukup besar untuk biaya promosi. Media atau alat promosi yang sering dilakukan perusahaan antara lain melalui : Periklanan, Penjualan Personal, Pemasaran langsung, Hubungan masyarakat, dan Promosi penjualan. Alat-alat promosi tersebut dapat digunakan sesuai dengan kebutuhan dan kemampuan dari perusahaan itu sendiri.

Dalam pemasaran kita tidak cukup dengan hanya menciptakan pemasaran yang baik, menetapkan harga yang menarik dan membuat promosi yang tersedia bagi pelanggan, keputusan pembelian pun sangat berpengaruh terhadap keberhasilannya suatu perusahaan dalam memasarkan produknya. 
Menurut Kotler (2010) keputusan pembelian mempunyai struktur sebanyak tujuh komponen, yaitu: keputusan tantangan jenis produk, konsumen dapat mengambil keputusan untuk membeli sebuah produk atau menggunakan uangnya untuk tujuan yang lain (dalam hal ini perusahaan memberikan alternatif lainnya yang akan dipertimbangkan konsumen). Keputusan tentang bentuk produk, konsumen dapat mengambil keputusan untuk membeli atau menggunakan produk tertentu, pemasar harus mengetahui kesukaan konsumen tentang produk yang bersangkutan untuk memaksimumkan daya tarik. Pembelian konsumen pada alfamart cabang Pondok Pucung-Kota Tangerang Selatan mengalami penurunan jumlah pembelian dari tahun-tahun sebelumnya.

Melihat kondisi tersebut maka sangat dibutuhkan bagi perusahaan untuk merencanakan dan mengantisipasi terhadap situasi dan kondisi yang sedang terjadi, agar tujuan perusahaan untuk mempertahankan dan meningkatkan hasil penjualan tercapai. Ruang lingkup promosi yang sangat kecil, adanya pesaing waralaba yang sejenis dan media promosi yang terbatas dapat mempengaruhi keputusan pembelian yang ada di perusahaan tersebut. Kegiatan promosi penjualan dipercaya sebagai sebuah langkah dalam strategi pemasaran yang dapat meningkatkan minat dan daya beli masyarakat.

Dari uraian tersebut diatas maka penulis tertarik untuk mrmbahas dan menganalisis tentang: "Pengaruh Strategi Promosi Terhadap Keputusan Pembelian Konsumen Pada Alfamart Cabang Pondok Pucung-Kota Tangerang Selatan".

\section{B. Rumusan Masalah}

1. Bagaimana strategi promosi pada Alfamart Pondok Pucung-Kota Tangerang Selatan ?.

2. Bagaimana keputusan pembelian pada Alfamart Pondok Pucung-Kota Tangerang Selatan?.

3. Adakah pengaruh antara strategi promosi terhadap keputusan pembelian pada Alfamart Pondok Pucung-Kota Tangerang Selatan ?.

\section{Tujuan Penelitian}

1. Untuk mengetahui kondisi strategi promosi pada Alfamart Pondok Pucung-Kota Tangerang Selatan.

2. Untuk mengetahui kondisi keputusan pembelian pada Alfamart Pondok Pucung-Kota Tangerang Selatan.

3. Untuk mengetahui pengaruh strategi promosi terhadap keputusan pembelian pada Alfamart Pondok Pucung-Kota Tangerang Selatan.

\section{TINJAUAN PUSTAKA}

\section{Strategi promosi}

Menurut Fandy Tjiptono (2012) Kualitas pelayanan menggambarkan pelayanan yang didapat oleh pelanggan untuk memenuhi kebutuhan produk yang dibelinya ataupun saat menghadapi permasalahan dengan produk layanan tersebut. Indikator yang dipakai meliputi tangible, reliability, responsiveness, assurance dan empathy.

\section{Keputusan Pembelian}

Menurut Kotler \& Keller (2012) Kepuasan pelanggan dalam penelitian ini adalah evaluasi dari keseluruhan kinerja yang diberikan perusahaan dalam memberikan pelayanan, memenuhi harapan dan keinginan pelanggan. Indikator yang dipakai meliputi memenuhi harapan, memenuhi kebutuhan, kesetiaan pada produk, merekomendasikan 
dan menawarkan gagasan atau ide.

\section{METODE PENELITIAN}

\section{Populasi}

Populasi dalam penelitian ini berjumlah 100 responden Alfamart Pondok PucungKota Tangerang Selatan

2. Sampel

Teknik pengambilan sampling dalam penelitian ini adalah sampel jenuh, dimana semua anggota populasi dijadikan sebagai sampel. Dengan demikian sampel dalam penelitian ini sampel yang digunakan berjumlah 100 responden.

\section{Jenis Penelitian}

Jenis penelitian yang dipakai adalah asosiatif, dimana tujuannya adalah untuk mengetahui atau mencari keterhubungan antara variabel independen terhadap variabel dependennya

\section{Metode Analisis Data}

Dalam menganalisis data digunakan uji validitas, uji reliabilitas, analisis regresi linier sederhana, analisis koefisien korelasi, analisis koefisien determinasi dan pengujian hipotesis.

\section{HASIL PENELITIAN}

\section{Analisis Deskriptif}

Pada pengujian ini digunakan untuk mengetahui skor minimum dan maksimum skor tertinggi, ratting score dan standar deviasi dari masing-masing variabel. Adapun hasilnya sebagai berikut:

Tabel 1. Hasil Analisis Descriptive Statistics

Descriptive Statistics

\begin{tabular}{ll|r|r|r|r} 
& N & \multicolumn{1}{c|}{ Minimum } & Maximum & Mean & \multicolumn{1}{c}{ Std. Deviation } \\
\hline Strategi promosi (X) & 100 & 28 & 44 & 34.14 & 3.864 \\
\hline Keputusan Pembelian (Y) & 100 & 29 & 49 & 38.41 & 4.238 \\
\hline Valid N (listwise) & 100 & & & & \\
\hline
\end{tabular}

Strategi promosi diperoleh varians minimum sebesar 28 dan varians maximum 44 dengan ratting score sebesar 3,414 dengan standar deviasi 3,864. Skor ini termasuk pada rentang sakala 3,40-4,19 dengan kriteria baik atau setuju.

Keputusan pembelian diperoleh varians minimum sebesar 29 dan varians maximum 49 dengan ratting score sebesar 3,841 dengan standar deviasi 4,238. Skor ini termasuk pada rentang sakala 3,40 - 4,19 dengan kriteria baik atau setuju.

\section{Analisis Kuantitatif}

Pada analisis ini dimaksudkan untuk mengetahui pengaruh variabel independen terhadap variabel dependen. Adapun hasil pengujian sebagai berikut:

\section{a. Analisis Regresi Linier Sederhana}

Uji regresi ini dimaksudkan untuk mengetahui perubahan variabel dependen jika variabel independen mengalami perubahan. Adapun hasil pengujiannya sebagai berikut:

Tabel 2. Hasil Pengujian Regresi Linier Sederhana

$$
\text { Coefficients }^{\mathrm{a}}
$$

\begin{tabular}{l|l} 
Unstandardized & Standardized
\end{tabular}

Coefficients Coefficients

\begin{tabular}{lr|r|r|r|r} 
Model & \multicolumn{1}{c}{ B } & Std. Error & Beta & \multicolumn{1}{c}{$\mathrm{t}$} & \multicolumn{1}{c}{ Sig. } \\
\hline 1 (Constant) & 9.323 & 2.397 & & 3.889 & .000 \\
\hline Strategi promosi $(\mathrm{X})$ & .852 & .070 & .777 & 12.209 & .000 \\
\hline
\end{tabular}


Berdasarkan hasil pengujian pada tabel di atas, diperoleh persamaan regresi $\mathrm{Y}$ $=9,323+0,852 X$. Dari persamaan tersebut dijelaskan sebagai berikut:

1) Konstanta sebesar 9,323 diartikan jika strategi promosi tidak ada, maka telah terdapat nilai keputusan pembelian sebesar 9,323 point.

2) Koefisien regresi strategi promosi sebesar 0,852, angka ini positif artinya setiap ada peningkatan strategi promosi sebesar 0,852 point maka keputusan pembelian juga akan mengalami peningkatan sebesar 0,852 point.

\section{b. Analisis Koefisien Korelasi}

Analisis koefisien korelasi dimaksudkan untuk mengetahui tingkat kekuatan hubungan dari variabel independen terhadap variabel dependen. Adapun hasil pengujian sebagai berikut:

Tabel 3. Hasil Pengujian Koefisien Korelasi Strategi promosi Terhadap Keputusan Pembelian.

Correlations $^{\mathrm{b}}$

\begin{tabular}{llr|r} 
& & \multicolumn{1}{c}{$\begin{array}{c}\text { Strategi } \\
\text { promosi (X1) }\end{array}$} & \multicolumn{1}{c}{$\begin{array}{c}\text { Keputusan } \\
\text { Pembelian (Y) }\end{array}$} \\
\hline Strategi promosi (X) & Pearson Correlation & 1 & $.777^{* *}$ \\
\cline { 2 - 4 } & Sig. (2-tailed) & & .000 \\
\hline Keputusan Pembelian (Y) & Pearson Correlation & $.777^{* *}$ & 1 \\
\cline { 2 - 4 } & Sig. (2-tailed) & .000 & \\
\hline
\end{tabular}

Berdasarkan hasil pengujian diperoleh nilai korelasi sebesar 0,777 artinya strategi promosi memiliki hubungan yang kuat terhadap keputusan pembelian.

\section{c. Analisis Koefisien Determinasi}

Analisis koefisien determinasi dimaksudkan untuk mengetahui besarnya persentase pengaruh dari variabel independen terhadap variabel dependen. Adapun hasil pengujian sebagai berikut:

Tabel 4. Hasil Pengujian Koefisien Determinasi Strategi promosi Terhadap Keputusan Pembelian.

Model Summary

\begin{tabular}{|c|c|c|c|c|}
\hline Model & $\mathrm{R}$ & R Square & $\begin{array}{l}\text { Adjusted R } \\
\text { Square }\end{array}$ & $\begin{array}{c}\text { Std. Error of the } \\
\text { Estimate }\end{array}$ \\
\hline 1 & $.777^{\mathrm{a}}$ & .603 & .599 & 2.683 \\
\hline
\end{tabular}

Berdasarkan hasil pengujian diperoleh nilai determinasi sebesar 0,603 artinya strategi promosi memiliki kontribusi pengaruh sebesar 60,3\% terhadap keputusan pembelian, sedangkan sisanya sebesar $39,7 \%$ dipengaruhi oleh faktor lain yang tidak dilakukan penelitian.

\section{d. Uji Hipotesis}

Pengujian hipotesis dengan uji t digunakan untuk mengetahui hipotesis mana yang diterima.

Rumusan hipotesis: Terdapat pengaruh yang signifikan strategi promosi terhadap keputusan pembelian.

Tabel 5. Hasil Uji Hipotesis Strategi promosi Terhadap Keputusan Pembelian.

Coefficients $^{\mathrm{a}}$

Unstandardized

Coefficients

Standardized

Coefficients

\begin{tabular}{llr|r|r|r|r}
\multicolumn{2}{l}{ Model } & \multicolumn{1}{c}{ B } & Std. Error & Beta & \multicolumn{1}{c}{$\mathrm{t}$} & \multicolumn{1}{c}{ Sig. } \\
\hline \multirow{2}{*}{1} & 9.323 & 2.397 & & 3.889 & .000 \\
\cline { 2 - 7 } & Strategi promostant $(\mathrm{X})$ & .852 & .070 & .777 & 12.209 & .000 \\
\hline
\end{tabular}


Berdasarkan hasil pengujian pada tabel di atas, diperoleh nilai t hitung $>\mathrm{t}$ tabel atau $(12,209>1,984)$, dengan demikian hipotesis yang diajukan bahwa terdapat pengaruh yang signifikan atara strategi promosi terhadap keputusan pembelian diterima.

\section{Pembahasan Hasil Penelitian}

\section{Kondisi Jawaban Responden Variabel Strategi promosi}

Berdasarkan jawaban responden, variabel strategi promosi diperoleh ratting score sebesar 3,414 berada di rentang skala 3,40 - 4,19 dengan kriteria baik atau setuju.

\section{Kondisi Jawaban Responden Variabel Keputusan Pembelian}

Berdasarkan jawaban responden, variabel keputusan pembelian diperoleh ratting score sebesar 3,841 berada di rentang skala 3,40 - 4,19 dengan kriteria baik atau setuju.

\section{Pengaruh Strategi promosi Terhadap Keputusan Pembelian}

Strategi promosi berpengaruh signifikan terhadap keputusan pembelian dengan persamaan regresi $\mathrm{Y}=9,323+0,852 \mathrm{X}$, nilai korelasi sebesar 0,777 atau memiliki hubungan yang kuat dengan kontribusi pengaruh sebesar 60,3\%. Pengujian hipotesis diperoleh nilai $t$ hitung $>t$ tabel atau $(12,209>1,984)$. Dengan demikian hipotesis yang diajukan bahwa terdapat berpengaruh signifikan antara strategi promosi terhadap keputusan pembelian diterima.

\section{KESIMPULAN DAN SARAN}

\section{Kesimpulan}

a. Variabel strategi promosi diperoleh ratting score sebesar 3,414 berada di rentang skala 3,40 - 4,19 dengan kriteria baik atau setuju.

b. Variabel keputusan pembelian diperoleh ratting score sebesar 3,841 berada di rentang skala 3,40 - 4,19 dengan kriteria baik atau setuju.

c. Strategi promosi berpengaruh signifikan terhadap keputusan pembelian dengan persamaan regresi $\mathrm{Y}=9,323+0,852 \mathrm{X}$, nilai korelasi sebesar 0,777 atau kuat dan kontribusi pengaruh sebesar 60,3\% sedangkan sisanya sebesar 39,7\% dipengaruhi faktor lain. Uji hipotesis diperoleh nilai t hitung > t tabel atau $(12,209>1,984)$.

\section{Saran}

Berdasarkan hasil penelitian di atas, maka penulis memberikan saran sebagai berikut:

a. Alfamart harus selektif dan mampu memilih media dan strategi dalam melakukan program promosi agar mampu menarik konsumen untuk melakukan pembelian.

b. Perusahaan harus selalu melakukan survey terkait kepuasan konsumen agar dapat diketahui aspek mana yang perlu diperbaiki.

\section{DAFTAR PUSTAKA}

Algifari. (2015). “Analisis Regresi untuk Bisnis dan Ekonomi”. Yogyakarta: BPFE.

Arikunto, Suharsimi (2014). "Prosedur Penelitian Suatu Pendekatan Praktek". Jakarta: Rineka Cipta.

Asih, P. S., et al. 2021). Analisis Faktor-Faktor Yang Mempengaruhi Keputusan Pembelian Produk Fastfood KFC Di Kota Sorong (Studi Kasus Mega Mall Kota Sorong). Jurnal Ilmiah PERKUSI, 1(3), 352-356. 
Bashu Swastha dan T. Handoko (2015) Manajemen Pemasaran Moderen, Yogyakarta: BPFE.

Basu Swastha Dharmmesta. (2014). Manajemen Pemasaran. BPFE: Yogyakarta. Buchari Alma. 2014. Manajemen pemasaran dan Pemasaran Jasa. Edisi Revisi.

Bilson Simamora (2016) Panduan Riset Prilaku Konsumen, Jakarta: PT. Gramedia Pustaka.

Fandy Tjiptono (2017), Serivce Quality and Satisfiation. Jakarta: Edisi tiga. Andi.

Freddy Rangkuti (2016) Strategi Promosi Yang Kreatif, Edisi Pertama, Cetakan Pertama Jakarta: Gramedia Pustaka Utama.

Imam Ghozali (2017). "Aplikasi Analisis Multivariate Dengan Program SPSS”. Edisi Kelima. Semarang: Badan Penerbit Undip.

Istijanto (2014) “Riset Sumber Daya Manusia”. Jakarta: PT. Gramedia Pustaka

Kharis, Ismu Fadli (2011). "Studi Mengenai Impulse Buying dalam Penjualan Online”. Semarang : Skripsi Universitas Diponegoro

Kotler dan Amstrong (2017), Prinsip-prinsip Pemasaran. Edisi Kedua Belas”. Jilid Satu. Jakarta: Erlangga.

Lupiyoadi (2016) Manajemen Pemasaran Jasa, Edisi 4, Jakarta: Salemba Empat.

Maddinsyah, A., et al. (2020). Desain Formulasi Dan Implementasi Bisnis Strategik Dengan Pendekatan Business Model Canvas (BMC) Terintegrasi Kerangka Integrated Performance Management System (IPMS) Pada Koperasi Asperindo. Inovasi, 7(2), 67-76.

Mani, J. (2017). Pengaruh Persepsi Merek Dan Strategi promosi Terhadap Kepuasan Pelanggan (Studi Kasus Pada PT. Bisma Narendra Di Jakarta). Jurnal Mandiri, 1(2), 187-206.

Nurjaya, N., et al. (2021). Pengaruh Brand Image Terhadap Keputusan Pembelian Pada PT. Wahana Motor Di Wilayah Cianjur. Jurnal Ilmiah PERKUSI, 1(2), 291-296.

Philip Kotler (2017) Manajemen Pemasaran, Edisi Keempat Belas, Jakarta: PT. Indeks.

Phipil Kotler dan Kevin Keller (2017) Manajemen Pemasaran, Edisi Kedua Belas, Jilid Satu, Jakarta: Erlangga.

Rao, Purba, (2012). "Measuring Consumer Perceptions Through Factor Analysis”, The Asian.

Rofianto, W., et al. (2021). Cultural Product Branding, Antecedents, And Its Implications: A Study On The Context Of Indonesian Batik. International Journal Of Social, Policy And Law, 2(2), 37-46.

Santoso, Singgih (2015). "Menguasai Statistik Multivariat". Jakarta: PT Elex Media Komputindo.

Sudjana (2014) “Metode Statistika”, Bandung: Tarsido.

Sugiyono (2017), "Metode Penelitian Administrasi : dilengkapi dengan Metode $R \&$ D”. Bandung: Alfabeta.

Suhartanto (2014). "Metode Riset Pemasaran”. Bandung: Alfabeta

Wangsi, M. M., et al. (2018). Perlindungan Konsumen Dalam Pelabelan Produk Menurut Ekonomi Islam. Sentralisasi, 7(1), 1-9. 